\title{
Exploring the technological pedagogical and content knowledge (TPACK) of Taiwanese university physics instructors
}

\author{
Syh-Jong Jang \\ Asia University, Taiwan \\ Yahui Chang \\ Shaanxi Normal University, China
}

\begin{abstract}
University science teachers' technological pedagogical and content knowledge (TPACK) is crucial for effective teaching. Although there has been a plethora of studies investigating pre-service and in-service teachers' TPACK, few studies have examined university instructors' TPACK and university students' perceptions of instructors' TPACK. The main purpose of this study was to examine the TPACK questionnaire differences between university students' perceptions and instructors' self-perceptions, and assess differences in university physics instructors' TPACK according to gender, academic degrees and teaching experience in Taiwan. This study adopted and revised an instrument for measuring university students' perceptions of science instructors' TPACK. The sample was randomly selected from the physics instructors of universities in the northern, central, and southern regions of Taiwan. Exploratory factor analysis was conducted to examine the dimensions of the instrument. The results revealed that the TPACK questionnaire of university physics instructors' views were different from the university students' perceptions. University physics instructors' results indicated statistical significance in overall TPACK according to teaching experience. The research implications of this study are provided along with suggestions.
\end{abstract}

\section{Introduction}

Most university science instructors entering the profession may find their initial teaching efforts stressful, but with experience, they acquire a repertoire of teaching strategies and representations that they draw on throughout their teaching. The underlying rationale is that university instructors play a key role in ensuring the quality of higher education (Jang, 2011). Furthermore, unlike K-12 schoolteachers who have received formal teacher education training, university instructors need to keep developing their teaching methods and strategies while enriching their area of expertise. Abell, Rogers, Hanuscin, Lee and Gagnon (2009) pointed out that novice university instructors are especially susceptible to teaching difficulties because most doctoral programs do not provide any pedagogical training or practicum opportunities as commonly seen in teacher education programs. Similarly, Jaskyte, Taylor, and Smariga (2009) stated that the majority of doctoral programs emphasise research skills but ignore teaching methods and curriculum design. Consequently, many novice college instructors do not know how to transform their expertise into teachable formats. In order to investigate factors affecting teaching efficacy and teaching difficulties, scholars have recommended defining codifiable teacher knowledge. As part of this trend, Shulman's (1986, 1987) pedagogical content knowledge (PCK) has been described as a knowledge base necessary for effective teaching in many educational reform documents (American Association for the Advancement of Science [AAAS], 1993; National Research Council [NRC], 1996).

In today's world, it cannot be denied that educational technology is gradually playing a critical role in our lives, particularly because applications of technology to learning environments are closely linked to students' learning achievement (Kopcha, 2010). Angeli and Valanides (2009) suggested that if teachers make good and proper use of information and communication technology (ICT), it is possible to create better learning environments for students. Nevertheless, successful incorporations of ICT into instruction are not that simple. Unlike merely adding a new technology to classroom instructions, applying ICT to classrooms requires teachers to simultaneously have sufficient pedagogical content knowledge and technological knowledge to maximise teaching effectiveness and efficiency. In line with this, numerous studies have focused on the issues of technological pedagogical and content knowledge (TPACK) to help teachers achieve more positive and preferable teaching and learning. 
TPACK, which was proposed by Mishra and Koehler (2006), has been one of the focal points in recent educational technology studies (Archambault \& Barnett, 2010; Jimoyiannis, 2010; Koh, Chai, \& Tay, 2014). Generally, there have been two research streams in previous TPACK studies. One research stream is related to pre-service and in-service teachers' TPACK, and another is associated with students' perceptions of teachers' TPACK. Although there has been a plethora of studies investigating pre-service and in-service teachers' TPACK (Angeli \& Valanides, 2009; Chai, Koh, \& Tsai, 2010, 2013; Chen \& Jang, 2014; Jang \& Tsai, 2012; Koh, Chai, \& Tsai, 2010; Lee \& Tsai, 2010; Lin, Tsai, Chai, \& Lee, 2013; Niess, 2005; Voogt, Fisser, Roblin, Tondeur, \& van Braak, 2013), few studies have examined university instructors and university students' perceptions of instructors' TPACK (Chang, Jang, \& Chen, 2015; Jang \& Chen, 2013). According to Tuan, Chang, Wang, \& Treagust (2000), student perceptions of teachers’ knowledge may provide rich information about students' cognition and classroom processes. Jaskyte et al. (2009) suggested the views of both university teacher and students are important sources when we intend to examine teacher knowledge in classroom contexts. We contend, while students' perceptions may not be the same as teachers' self-perceptions, they provide a relatively objective account and alternative view supplementing traditional teacher self-reports. Another benefit of student-perceived instruments is that they make it easier to collect large samples for research. University students may know enough to express their views of teachers' performance and are key stakeholders in the educational field (Jang, 2011). Their perceptions of teachers' TPACK not only merit further investigation in this study, but may also shed more light on future TPACK development.

Considering the key influence of this research gap between university instructors and university students' perceptions of science instructors' TPACK, the main purpose of this study was to examine the university students' perceptions and instructors' self-perceptions of TPACK questionnaire differences, and assess the differences of university physics instructors' TPACK according to gender, academic degrees and teaching experience in Taiwan.

\section{Research questions}

Based on the purposes of this study, we proposed two research questions:

1. Do university students' perceptions and instructors' self-perceptions differ in a TPACK questionnaire of university physics instructors?

2. Does the TPACK of university physics instructors differ according to academic degrees, gender, and teaching experience?

\section{The TPACK conceptual framework}

The conceptualisation of TPACK is mainly derived from the theoretical framework of PCK. It has been shown that teachers' PCK, containing at least pedagogical knowledge and subject matter knowledge, could be highly associated with teaching effectiveness and efficiency (Shulman, 1986, 1987). Niess (2005) indicated teachers' PCK is an integration and interaction of teaching knowledge and subject matter knowledge. Jang and Chen (2010) added:

PCK involves the transformation of other types of knowledge (subject matter knowledge, pedagogical knowledge, and knowledge of context) into viable instruction so that it can be used effectively and flexibly in the communication process between teachers and learners during classroom practice. (p. 554)

In other words, PCK not only stresses the important role of teachers' pedagogical knowledge and subject matter knowledge in instruction, but also emphasises teachers' understanding of student learning capabilities and obstacles. Van Driel, Verloop, and de Vos (1998) suggested that all scholars agree on Shulman's two knowledge components: (1) knowledge of representations of subject matter, and (2) understanding of specific learning difficulties and student conceptions. Although there is no accurate and precise definition of PCK, generally, it is agreed that the content of PCK could broadly include "teachers' 
knowledge of representations of subject matter, and their knowledge of learners' conceptions and content-related difficulties” (Angeli \& Valanides, 2009; p.156).

The TPACK framework was built upon Shulman's PCK to include technology knowledge as intersecting with content and pedagogical knowledge (Mishra \& Koehler, 2006). It is shown that teachers' technological knowledge is another critical component that could be highly associated with teaching effectiveness and efficiency (Angeli \& Valanides, 2009; Archambault \& Barnett, 2010; Chai et al., 2010, 2013; Jimoyiannis, 2010). More noteworthy, the initial conceptualisation of TPACK has extrapolated technological content knowledge (TCK), technological pedagogical knowledge (TPK), and technological pedagogical content knowledge (TPCK), as three potential and additional components that could be closely connected with teaching effectiveness and efficiency. Although the inceptive theoretical framework of TPACK seems promising and attractive, the complex, unclear, and untenable TPACK framework has remained a tricky problem in present studies (Angeli \& Valanides, 2009; Archambault \& Barnett, 2010; Jimoyiannis, 2010).

In view of these deficiencies, several studies have attempted to further clarify the ambiguities within the definition and framework of TPACK. For example, Schmidt et al. (2009) explored the TPACK framework by further investigating pre-service teachers' perceptions of TPACK. The survey went through factor and item analyses, and expert reviews for content validity. The instrument may help educators design longitudinal studies to assess pre-service teachers' development of TPACK. Based on the work of Schmidt et al. (2009), Chai et al. (2010) revised the instrument and recruited 889 pre-service teachers to investigate their perceptions of teachers' TPACK. They suggested a way of achieving a confirmatory factor model fit by omitting three intermediary knowledge constructs (PCK, TCK, and TPK). Although they were able to obtain a four-factor model with good fit indexes, although this four-factor model (TK, CK, PK, and TPACK) may limit one's understanding of the intermediary stages of TPACK formation.

Koh, Chai, \& Tsai (2013) further used a structural equation model based on Mishra and Koehler's (2006) TPACK framework to describe the TPACK perceptions of 455 practicing teachers in Singapore. The study showed that teachers, perceived TPACK to be formulated from the direct effects of technological knowledge and pedagogical knowledge. They also perceived these knowledge sources to contribute to the development of technological pedagogical knowledge and technological content knowledge, which also contributed to their TPACK. In these teachers' conceptions of TPACK however, the effects of content knowledge and pedagogical content knowledge were not evident.

Lin et al. (2013) conducted a study to develop a TPACK questionnaire particularly examining the TPACK of Singaporean in-service and pre-service science teachers'. The researchers confirmed the seven factors of TPACK (i.e., TK, PK, CK, TCK, TPK, PCK, and TPC). Correlations showed that teachers' perceptions on TPC indicated a significant and positive correlation with the other six factors. They also found that female teachers showed higher self-confidence in PK and lower self-confidence in TK compared to male teachers. Age of in-service female teachers was significantly and negatively correlated with their perceptions of TK, TPK, TCK, and TPC.

In addition, previous studies have focused heavily on the theoretical development of TPACK mainly due to the complex and unclear framework (Angeli \& Valanides, 2009; Archambault \& Barnett, 2010; Jimoyiannis, 2010). Angeli and Valanides (2009) argued the boundaries between some components of TPACK. For example, what they define as TCK and TPK, are fuzzy, indicating a weakness in accurate knowledge categorisation or discrimination, and, consequently, a lack of precision in the framework. Jang and Tsai (2012) studied Taiwanese elementary mathematics and science teachers' TPACK in terms of interactive white board (IWB) usage. Exploratory factor analysis showed that while TK and CK were clearly identified, items from PK and PCK were loaded together and items from TPK, TCK, and TPACK were loaded as a group. Archambault and Barnett (2010) tested online teachers' perceptions of TPACK. They revisited and explored the TPACK framework by using factor analysis based on using a survey with 24 items designed to measure each of the areas described by the TPACK framework. While the framework is helpful from an organisational standpoint, it is difficult to split up each of the technology-related domains. 


\section{Evaluation of university faculty knowledge}

Research on university instructors' TPACK is scant in comparison with that of research on pre-service or K-12 school teachers. Shih and Chuang (2013) developed and validated an instrument for assessing university students' perceptions of faculty knowledge (SPFK) in technology-supported classroom environments. A total of 50 items in 4 constructs were developed for the instrument. The construct validity of this instrument was examined through confirmatory factor analysis. After checking the construct structure of the instrument, the multidimensional version of the rating scale model (MRSM) was used to analyse item response data. Results showed that after the elimination of item 17, the 49-item instrument for assessing university students’ perceptions of faculty knowledge was validated.

Within undergraduate physics, few studies, to our knowledge, have examined students' perceptions of physics instructors' TPACK. Some studies have looked at the influence that teacher-related epistemological factors have on student approaches to learning (Edmondson \& Novak 1993, Hammer, 1994). Marshall and Linder (2005) studied expectations of teaching among undergraduate physics students. They identified and exemplified five qualitatively different expectations of physics teaching. These range from presenting knowledge, developing understanding, widening conceptual application, promoting intellectual independence and critical thinking, and facilitating personal development and agency. Jang, Tsai, and Chen (2013) used a research model to assess and compare university students' perceptions' of a novice and an experienced physics instructor's PCK. The results showed that each instructor's PCK performance in four categories was slightly improved, though the difference was not statistically significant and only the category of instructional representation and strategies was found to be statistically different according to students' evaluations of their instructor's PCK.

These reviews suggest there have yet to be quantitative studies directly investigating the TPACK of university instructors or university students' perceptions of physics instructors. Jang and Chen (2013) saw these deficiencies and first conducted a review of the literature on both PCK and TPACK. Five main categories of teacher knowledge were identified to investigate dimensions of TPACK, namely Subject Matter Knowledge (SMK), Instructional Representation and Strategies (IRS), Instructional Objective and Context (IOC), Knowledge of Students' Understanding (KSU), and Technology Integration and Application (TIA). They addressed 317 science college students to further examine their perceptions of teachers' TPACK. Through factor analysis, which deviated slightly from the original five dimension framework, they found that the four new dimensions captured the Taiwanese university contexts even better. These dimensions included SMK, IRS, KSU, and TIA presented in the 33-item TPACK instrument. It was also shown that the SMK factor of $\alpha=.943$, IRS factor of $\alpha=.949$, KSU factor of $\alpha=.902$, and TIA factor of $\alpha=.942$ all indicated satisfactory internal consistency. This TPACK instrument achieved satisfactory content and construct validity. First, they conducted an intensive review of empirical studies and existing questionnaires in order to establish the theoretical grounds for the TPACK instrument. Furthermore, the items have been subjected to multiple revisions according to: (1) student reviews of readability and clarity of narrations; (2) expert reviews of coverage and conceptual accuracy; (3) item analysis for screening poor items; and (4) factor analysis for re-evaluating dimensions of TPACK in a college context.

\section{Methodology}

\section{Instrumentation}

This study adopted and revised the 33-item instrument developed by Jang and Chen (2013) to measure university students' perceptions of instructors' TPACK. A 5-point Likert scale response with anchors-, including 1 = Never, 2 = Seldom, 3 = Sometimes, 4 = Often, 5 = Always, was utilised to measure the variables in each TPACK construct. Four main categories of teacher knowledge were identified to investigate dimensions of TPACK. SMK includes not only facts and concepts but also the structures and rules that incorporate those facts and concepts. IRS includes various representations (e.g., analogies, illustrations, examples, explanations, demonstrations, and hints) of the concepts, and design curricula and activities for instruction. KSU helps teachers identify the general preferences of their students as well as individual differences within the class. TIA includes an overarching conception of their subject matter with respect to technology and what it means to teach with technology. The version of the TPACK 
instrument related to university students' perceptions contains 33 items in four dimensions: (1) SMK, 10 items; S1-S10; (2) IRS, 10 items: S11-S20; (3) KSU, 6 items: S21-S26; and (4) TIA, 7 items: S27-S33. (See Appendix A)

In order to develop the questionnaire for university physics instructors' self-perceptions of their TPACK, we changed the "I think my teacher" in the questions of Jang and Chen's (2013) instrument to "I". For example:

S1. I think my teacher knows the content he/she is teaching, and

S27. I think my teacher knows how to use multimedia (e.g. PowerPoint and animation, etc.) for teaching.

Were revised to:

T1. I know the content I am teaching, and

T27. I know how to use multimedia (e.g. PowerPoint and animation, etc.) for teaching.

The other questions were changed in the same way. In the university instructor's TPACK questionnaire, the personal information section included academic degrees, gender and teaching experiences in physics. Factor analysis was conducted with the results of the questionnaire from the physics instructors, to verify whether the TPACK questionnaire developed by Jang \& Chen (2013) for university students fits in the context of the study (i.e., with university instructors). The entire TPACK instrument is presented in Appendices A and B.

\section{Participants and data collection}

The TPACK questionnaire sample was randomly distributed to physics instructors at universities in northern, central, and southern Taiwan. The targets were the university instructors who have taught or are teaching semester long, general physics courses. Evaluation on the TPACK of physics instructors was carried out according to their teaching of general physics courses. The universities were numbered and simple random sampling was used to select the schools participating in the study. In order to collect more university physics instructors' responses, we sent emails along with the questionnaire to individual physics instructors. As physics instructors volunteered to participate in the study, the numbers of the complete questionnaires varied. A total of 182 university instructors completed the TPACK questionnaire for this study. Comrey (1988) argued that "[a] sample size of 200 is reasonably good for ordinary factor-analytic work with 40 or fewer variables. More variables require larger samples (p. 758)”. Another criterion was proposed by Gorsuch (1983), who maintained that the minimum sample size should be five times the number of survey items. According to the above criteria, the number of participants in this study was sufficient to validate the questionnaire.

After questionnaires with incomplete basic personal information were excluded (i.e., gender, academic degree and teaching experience), 145 questionnaires remained, with all the TPACK questions completed. We used the data of the 145 physics instructors for further statistical analyses of teachers' TPACK according to gender, academic degrees and teaching experience.

\section{Data analysis}

Exploratory factor analysis was conducted to examine the dimensions of the instrument. The purposes of this were two-fold: to further verify the items within the questionnaire, and to examine the factorial validity of the questionnaire. We also used descriptive statistics of the physics instructors' questionnaires on TPACK. An independent samples $t$-Test was conducted when there were two groups (i.e., gender and academic degrees) to be compared for TPACK. ANOVA was conducted when there were more than two groups (i.e., teaching experience) compared for TPACK. 


\section{Results}

\section{Factor analysis}

The Kaiser-Meyer-Olkin (KMO) measure of sampling adequacy and Bartlett's Test of Sphericity (BTS) are applied to the data prior to factor extraction to ensure the characteristics of the data set are suitable for exploratory factor analysis (Field, 2009). In this instrument, KMO was .890, above the minimum value of .5, and BTS was significant. The diagonals of the anti-image correlation matrix were all over .5 supporting the inclusion of each item in the factor analysis. Given these overall indicators, factor analysis was further conducted with all 33 items. Table 1 shows the first factor analysis and items within each factor. Nevertheless, we found items T6, T9, T14, T20, T21, T24, and T26 had loading values of less .50 on these factors, so we decided to eliminate these items. After deleting these 7 items, there were 26 items remaining. Factor analysis was conducted a second time with these 26 items. The items T5, T11 and T12 could not fit into the IRS component, so these items were deleted. Finally, factor analysis was conducted again by dividing the remaining 23 items into three factors (see Table 2). The finalised items of each component are provided for university physics instructors in Appendix B.

We compared the items within the three factors with those in the original four dimensions. Generally, those in the original SMK, TIA, IRS, and KSU categories corresponded with the three factors. Particularly, the KSU factor items disappeared and spread into both SMK and IRS factors. In order to compare instructors' and students' perceptions of differences, therefore, we kept using SMK, IRS and TIA as factor names.

Related to the SMK factor, the original items T1, T2, T3, T4, T7 and T8 were kept, while items T6 and T9 were deleted. More specifically, KSU item T22, “I know students' learning difficulties of subject before class”, and item T23, "My questions can evaluate students' understanding of a topic” fell into the SMK factor. Therefore, there were eight items in the new SMK factor. Related to TIA factor, all seven original items fell into the same factor. Therefore, we kept TIA as a new factor for university instructors.

Related to the IRS factor, the original KSU item T25 fell into the IRS dimension. The IRS factor included original items T13, T15, T16, T17, T18 and T19. Items T11, T12, T14 and T20 were deleted. Item T25, "I use different approaches (questions, discussion, etc.) to find out whether students understand”, and item T10, "My belief or value in teaching is active and aggressive", were also included. Therefore, there were eight items in the new IRS factor. We will discuss this in more detail in the Discussion section.

\section{Reliability and validity}

Cronbach's alpha was computed to assess the instrument's reliability. Results showed that all of the three subscales as well as the total scale had very high internal consistency. Internal consistencies of each component were: SMK $(\alpha=.87)$, IRS $(\alpha=.86)$, TIA $(\alpha=.90)$, and TPACK $(\alpha=.92)$. Although the factor analysis result deviated slightly from our original four-component framework, we found that the new three components captured Taiwanese university instructors' contexts even better. As such, we decided to finalise our scale items without further modifications. The final version of the TPACK instrument contains 23 items in three dimensions: (1) SMK, 8 items; (2) IRS, 8 items; (3) TIA, 7 items. The entire TPACK instrument for university instructors is presented in Appendix B.

\section{TPACK differences according to gender}

Table 3 shows descriptive statistics of the physics instructors' questionnaires on TPACK according to gender. Physics instructors indicated no statistical significance in overall TPACK according to gender. With the consideration of other TPACK sub-components, male physics instructors rated their SMK significantly higher than did female instructors, but female physics instructors rated their IRS significantly higher than did male instructors. 
Table 1

The first factor structure of TPACK instrument

\begin{tabular}{|c|c|c|c|c|}
\hline & \multicolumn{4}{|c|}{ Factor component } \\
\hline & 1 & 2 & 3 & 4 \\
\hline$\overline{\mathrm{T} 3}$ & .787 & & & \\
\hline T8 & .728 & & & \\
\hline $\mathrm{T} 1$ & .703 & & & \\
\hline T7 & .695 & & & \\
\hline $\mathrm{T} 4$ & .686 & & & \\
\hline $\mathrm{T} 2$ & .654 & & & \\
\hline T22 & .628 & & & \\
\hline T23 & .576 & & & \\
\hline T14 & .493 & & & \\
\hline T24 & .489 & & & \\
\hline T21 & .463 & & & \\
\hline T19 & & .785 & & \\
\hline T18 & & .764 & & \\
\hline T16 & & .687 & & \\
\hline T17 & & .610 & & \\
\hline T25 & & .542 & & \\
\hline T10 & & .520 & & \\
\hline T26 & & .491 & & \\
\hline T9 & & .396 & & \\
\hline T31 & & & .854 & \\
\hline T30 & & & .851 & \\
\hline T29 & & & .791 & \\
\hline T28 & & & .790 & \\
\hline T27 & & & .603 & \\
\hline T33 & & & .556 & \\
\hline T32 & & & .532 & \\
\hline T20 & & & .490 & \\
\hline T11 & & & & .777 \\
\hline T12 & & & & .714 \\
\hline T15 & & & & .520 \\
\hline $\mathrm{T} 5$ & & & & .510 \\
\hline T13 & & & & .505 \\
\hline T6 & & & & .296 \\
\hline
\end{tabular}


Table 2

The final factor structure of TPACK instrument

\begin{tabular}{|c|c|c|c|}
\hline & \multicolumn{3}{|c|}{ Factor component } \\
\hline & IRS & SMK & TIA \\
\hline$\overline{\mathrm{T} 16}$ & .778 & & \\
\hline T19 & .772 & & \\
\hline T18 & .761 & & \\
\hline $\mathrm{T} 15$ & .687 & & \\
\hline T13 & .635 & & \\
\hline $\mathrm{T} 17$ & .625 & & \\
\hline $\mathrm{T} 25$ & .517 & & \\
\hline $\mathrm{T} 10$ & .503 & & \\
\hline T3 & & .802 & \\
\hline T8 & & .761 & \\
\hline $\mathrm{T} 2$ & & .746 & \\
\hline $\mathrm{T} 1$ & & .731 & \\
\hline $\mathrm{T} 4$ & & .718 & \\
\hline $\mathrm{T} 7$ & & .683 & \\
\hline T22 & & .593 & \\
\hline $\mathrm{T} 23$ & & .548 & \\
\hline Т31 & & & .885 \\
\hline Т30 & & & .867 \\
\hline $\mathrm{T} 28$ & & & .807 \\
\hline T29 & & & .794 \\
\hline Т33 & & & .575 \\
\hline $\mathrm{T} 27$ & & & .566 \\
\hline Т32 & & & .557 \\
\hline
\end{tabular}

Table 3

Descriptive statistics of the physics instructors' questionnaires on TPACK according to gender

\begin{tabular}{cccccc}
\hline \multirow{2}{*}{ Components/Group } & \multicolumn{2}{c}{ Male } & \multicolumn{2}{c}{ Female } \\
& \multicolumn{2}{c}{$(n=124)$} & \multicolumn{2}{c}{$(n=21)$} & \\
\cline { 2 - 5 } & $M$ & $S D$ & $M$ & $S D$ & $t$ \\
\hline SMK & 4.49 & 0.45 & 4.26 & 0.44 & $2.19^{*}$ \\
IRS & 3.82 & 0.66 & 4.29 & 0.51 & $-3.18^{* *}$ \\
TIA & 3.76 & 0.86 & 4.01 & 0.76 & -1.22 \\
TPACK & 4.03 & 0.54 & 4.19 & 0.48 & -1.27 \\
\hline
\end{tabular}

Note. ${ }^{*} \mathrm{p}<.05,{ }^{* *} \mathrm{p}<.01$ 


\section{TPACK differences according to academic degrees}

Table 4 shows descriptive statistics of the physics instructors' questionnaires on TPACK according to what kind of academic degree they earned. Physics instructors indicated no statistical significance in overall TPACK according to academic degrees. With the consideration of other TPACK sub-components, physics instructors who have a doctoral degree in physics only rated their SMK significantly higher than did other instructors who do not have a doctoral degree in physics. Also physics instructors with physics doctoral degrees had higher average values in all three dimensions.

Table 4

Descriptive statistics of the physics instructors' questionnaires on TPACK according to academic degree Physics doctorate Other doctorate

\begin{tabular}{cccccc} 
Components/Group & \multicolumn{2}{c}{$(n=71)$} & \multicolumn{2}{c}{$(n=74)$} & \multirow{2}{*}{$t$} \\
\cline { 2 - 5 } & $M$ & $S D$ & $M$ & $S D$ & $2.16^{*}$ \\
SMK & 4.54 & 0.44 & 4.38 & 0.46 & 0.36 \\
IRS & 3.90 & 0.62 & 3.87 & 0.69 & 0.8 \\
TIA & 3.85 & 0.81 & 3.74 & 0.89 & 0.56 \\
TPACK & 4.11 & 0.51 & 4.01 & 0.56 \\
\hline
\end{tabular}

Note. ${ }^{*} \mathrm{p}<.05$

\section{TPACK differences according to teaching experience}

University physics instructors indicated statistical significance in overall TPACK according to teaching experience (see Table 5). As to examine each single sub-component, experienced physics instructors rated their SMK and IRS significantly higher than did novice physics instructors. Particularly, instructors with more than 26 teaching experiences had the highest average value in the SMK component, and instructors with 16-25 teaching experiences had the highest average value in the IRS component of TPACK.

Table 5

Descriptive statistics of the physics instructors' questionnaires on TPACK according to teaching experience

\begin{tabular}{|c|c|c|c|c|c|c|c|c|c|}
\hline \multirow[t]{2}{*}{ Components/Group } & \multicolumn{2}{|c|}{$\begin{array}{c}<5 \\
(n=26)\end{array}$} & \multicolumn{2}{|c|}{$\begin{array}{c}6-15 \\
(n=74)\end{array}$} & \multicolumn{2}{|c|}{$\begin{array}{c}16-25 \\
(n=34)\end{array}$} & \multicolumn{2}{|c|}{$\begin{array}{c}>26 \\
(n=11)\end{array}$} & \multirow[b]{2}{*}{$F$} \\
\hline & $M$ & $S D$ & $M$ & $S D$ & $M$ & $S D$ & $M$ & $S D$ & \\
\hline SMK & 4.22 & 0.45 & 4.48 & 0.47 & 4.53 & 0.38 & 4.71 & 0.27 & $4.02 * *$ \\
\hline IRS & 3.70 & 0.64 & 3.82 & 0.68 & 4.17 & 0.57 & 3.91 & 0.58 & $3.20 *$ \\
\hline TIA & 3.51 & 0.91 & 3.85 & 0.84 & 3.93 & 0.79 & 3.73 & 0.63 & 1.43 \\
\hline TPACK & 3.82 & 0.57 & 4.05 & 0.54 & 4.22 & 0.48 & 4.13 & 0.4 & $2.90 *$ \\
\hline
\end{tabular}

Note. ${ }^{*} \mathrm{p}<.05,{ }^{* *} \mathrm{p}<.01$

\section{Discussion and implications}

\section{Differences between the university students' perceptions and instructors' perceptions}

SMK factor

The perception questionnaire for university physics professors developed by this study is different from 
the perception questionnaire for university students developed by Jang \& Chen (2013). First, two items are eliminated from the SMK factor. Item 6, "I think my teacher explains the impact of subject matter on society”, focuses on application of course content in society. Students intend to apply physics in life; however, professors suggest that the instruction might be a difficulty in real teaching.

In Item 9, “ I believe my teacher pays attention to students’ reaction during class and adjusts his/her teaching attitude”, students expect that professors can change their instructional attitude or method according to students' reactions; while professors suggest that it is unlikely since they are used to their instruction methods. It is found that students and professors have different perceptions of "life application and change of instructional attitude”.

IRS factor

Next, 4 items of the IRS factor are eliminated. In Item 14, "I think my teacher provides opportunities for me to express my views during class", students might have the opportunity to express their opinions, but professors suggest that physics is more difficult and they seize the time to continue making the progress. It seems that it is not easy to allow students to express themselves.

Item 20, "I think my teacher prepares some additional teaching materials", is the supplementary instructional material, and it seems that the item is acceptable. However, since the first factor analysis fell into the TIA factor, it lacked technology-related content. Therefore, item 20 is deleted. In addition, 2 items are eliminated in the same condition, including Item 11, appropriate example, and Item 12, familiar metaphor.

In IRS new factor for professors' questionnaire, we add two new items, including “different instructional orientation" (Item 25) and “teachers' active values” (Item 10). Professors suggest that with teachers' active values, they adopt more interesting instructional strategies and methods in physics courses. Therefore, professors classify them in the IRS factor, but students originally allocate them to KSU and SMK.

\section{KSU factor}

As to the first factor analysis of KSU, three items are eliminated. In Item 21, "I believe my teacher realises students' prior knowledge before class", students expect that before the class, professors can recognise their prior knowledge, while professors suggest that everyone has different levels and it seems that it is difficult to precisely recognise every student's prior knowledge.

In Item 24, "I think my teacher's assessment methods evaluate my understanding of the subject”, students expect that the evaluation can assess students' comprehension of courses, but professors suggest that traditional written tests are used commonly and there are not multiple assessments. In Item 26, "I believe my teacher's assignments facilitate my understanding of the subject”, students expect that their assignments can help or enhance comprehension in physics courses; however, professors suggest that in traditional assignments, students simply review the content and it is difficult to enhance their comprehension.

\section{TIA factor}

Finally, related to TIA factor, all seven original items related to university students' perceptions' technology knowledge fell into the same factor. That is, university students' perceptions' TIA factor is the same as for university instructors’ TIA factor.

The factor analysis of the 23-item TPACK instrument for university professors' perceptions revealed a three-factor structure, which is different from Jang and Chen's (2013) original four component framework for university students' perceptions. KSU dimension of this study has disappeared and its items are relegated into SMK and IRS categories. This result does not mean that knowledge of students' understanding (KSU) is non-existent or unimportant in higher education, but it does reflect the actual Taiwanese college instructors' contexts. Two items of KSU (Item 22 and 23) are allocated as new SMK factor. According to professors, "recognition of difficulty of subjects” (Item 22) and "answering students' questions" (Item 23) are allocated in subject matter knowledge (SMK), however, students allocate these two items in the assessment of KSU. Professors and students thus have the different perceptions. 
Currently, most professors adopt written tests and they are not familiar with different ways to assess students' learning. Therefore in this study, most of items of the KSU factor are eliminated. Teachers' knowledge of assessment includes knowledge of instructional goals, multiple evaluations and implementation and explanation (Hanuscin et al., 2011).

Physics instructors' TPACK according to gender, qualifications and teaching experience

University physics instructors' overall TPACK indicated no significant differences according to gender in this study. We further examined each of the university instructors' TPACK components according to gender and found that female instructors rated the IRS questionnaire items significantly higher than did male instructors. However, male instructors rated the SMK questionnaire items significantly higher than did female instructors. Gender differences for variables related to technology have been found by other research studies. Gender differences in PK and TK were found by Lin et al. (2013), showing that female science teachers had higher confidence in PK but lower confidence in TK than did male teachers. Different findings were revealed by Jang and Tsai (2012), suggesting that science teachers show significant differences in TPACK according to gender with the use of interactive whiteboards.

As for teaching experience, experienced physics instructors rated their SMK and IRS significantly higher than did novice instructors. Research on PCK suggests that experienced teachers generally show higher content and pedagogical knowledge the more years they teach; thus, greater subject matter knowledge and pedagogical knowledge could be developed by actual teaching experience (Jang, Tsai, \& Chen, 2013). Nilsson (2008) emphasised the role of teaching experience as a way of understanding better the complex entities that constitute a knowledge base for teaching. She draws attention to the value of science teachers participating in experiences that might contribute to the development of their PCK. This supports the view of TPACK in relation to teaching experience in this study.

Research also suggests varying results for teachers' TPACK in relation to teaching experience. For in-service teachers' TPACK on the use of Web-based technology, it was found that teachers with more teaching experience viewed their TPACK as being lower than teachers with less teaching experience (Lee \& Tsai, 2010). In the context of using interactive whiteboards, Jang and Tsai (2012) concluded that teachers with more teaching experience showed higher overall TPACK than did teachers with less teaching experience. From the current study, we could not make clear conclusions about what the differences are and the reasons behind the differences. Therefore further studies need to be conducted to examine how male and female teachers' SMK and IRS knowledge differs and how experienced and novice teachers differ for SMK and IRS.

Finally, physics professors who have a doctoral degree in physics rated their SMK significantly higher than did other professors who do not have a doctoral degree in physics. It is possibly because professors who have a doctoral degree in physics have rich physics content knowledge. In addition, it is not easy to evaluate the TPACK of physics teachers in universities. In the classroom, they represent the authority and they tend to be arrogant and they might overestimate their TPACK. The real TPACK might not be shown. Therefore it is necessary to apply other types of assessment, such as university students' perceptions of teachers' knowledge. By examining students' judgments, we can more objectively evaluate the instructional field. This is unlike traditional evaluation of teachers which is based on observation where the interview data might refer to few subjects (Jang, 2011; Jang, Tsai, \& Chen, 2013). Generally, university professors' perceived professional knowledge might be higher, while questionnaires measuring students' perceptions can balance their subjectivity. Currently most researchers adopting TPACK knowledge and learning questionnaires focus on teachers of secondary and elementary schools (Chai, Koh, \& Tsai, 2010, Jang \& Tsai, 2012; Lee \& Tsai, 2010). They rarely adopt questionnaires to study secondary and elementary students' perceptions. University students are certainly different from secondary and elementary students. They have more capacity to judge teachers or their instruction. Questionnaires for studying university students' perceptions could serve as another form of measurement to supplement teachers', peers' or experts' evaluations of TPACK.

\section{Conclusion and limitations}

In conclusion, the major contribution of this study included the construction of theoretical bases and the development of an instrument for assessing university physics instructors' perceptions of their TPACK. 
This study also revealed that the TPACK questionnaire of university physics instructors' views were different from the university students' perceptions. Furthermore, this study assessed the differences in university physics instructors' TPACK according to gender, qualifications and teaching experience, with the context being in Taiwan.

In order to effectively evaluate the TPACK of university instructors, however, the surveys of this study have some limitations. Quantitative presentation does not investigate factors or reasons behind instructors' TPACK in depth, nor does it allow for assessment of content-specific details. As such, the researchers will collect supplemental qualitative data in various ways, such as through interviews, observations, and the open-ended opinions of students, to cross-validate the instructors' TPACK for future study.

As to the limitations of this study, professors' responses are insufficient. This study distributed at least 300 invitation letters and reminder emails. Professors in Taiwan might be too arrogant in their profession or too busy. Questionnaires of university professors' or university students' perceptions can help to assess university science teachers' technology knowledge. The TPACK questionnaire used in this study can make up for inadequacies in the current evaluations of university teachers. At present, the questionnaire survey of university instructors at the end of the semester is a general evaluation of instruction rather than a teachers' professional knowledge. Applying the TPACK questionnaire survey of this study can significantly contribute to the current needs of higher education.

\section{References}

Abell, S., Rogers, M., Hanuscin, D., Lee, M., \& Gagnon, M. (2009). Preparing the next generation of science teacher educators: A model for developing PCK for teaching science teachers. Journal of Science Teacher Education, 20(1), 77-93.

American Association for the Advancement of Science. (1993). Benchmarks for science literacy. New York, NY: Oxford University Press.

Angeli, C., \& Valanides, N. (2009). Epistemological and methodological issues for the conceptualization, development, and assessment of ICT-TPCK: Advances in technological pedagogical content knowledge (TPCK). Computers \& Education, 52(1), 154-168.

Archambault, L. M., \& Barnett, J. H. (2010). Revisiting technological pedagogical content knowledge: Exploring the TPACK framework. Computers \& Education, 55(4), 1656-1662.

Chai, C. S., Koh, J. H. L., \& Tsai, C.-C. (2010). Facilitating pre-service teachers' development of technological, pedagogical, and content knowledge (TPACK). Educational Technology \& Society, 13 (4), 63-73.

Chai, C.-S., Koh, J. H.-L., \& Tsai, C.-C. (2013). A Review of Technological Pedagogical Content Knowledge. Educational. Technology \& Society, 16 (2), 31-51.

Chang, Y., Jang, S.-J., \& Chen, Y.-H. (2015). Assessing university students’ perceptions of their physics instructors' TPACK development in two contexts. British Journal of educational Technology, 46(6), 1236-1249.

Chen, Y.- H., \& Jang, S.-J. (2014). Interrelationship between stages of concern and technological, pedagogical, and content knowledge: A study on Taiwanese senior high school in-service teachers. Computers in Human Behavior, 32, 79-91.

Comrey, A. L. (1988). Factor-analytic methods of scale development in personality and clinical psychology. Journal of Consulting and Clinical Psychology, 56(5), 754-761.

Edmondson, K., \& Novak, J. (1993). The interplay of scientific epistemological views, learning strategies and attitudes of college students. Journal of Research in Science Teaching, 30(6), 547-559.

Field, A. (2009). Discovering statistics using SPSS. Thousand Oaks, CA: SAGE Publications Ltd.

Gorsuch, R. L. (1983). Factor analysis (2nd ed.). Hillsdale, NJ: Lawrence Erlbaum Associates.

Hammer, D. (1994). Students' beliefs about conceptual knowledge in introductory physics. International Journal of Science Education, 16(4), 385-403.

Hanuscin, D. L., Lee, M. H., \& Akerson, V. L. (2011). Elementary teachers' pedagogical content knowledge for teaching the nature of science. Science Education, 95(1), 145-167.

Jang, S. J. (2011). Assessing college students' perceptions of a case teacher's pedagogical content knowledge using a newly developed instrument. Higher Education, 61(6), 663-678.

Jang, S. J., \& Chen, K. C. (2010). From PCK to TPACK: Developing a transformative model for pre-service science teachers. Journal of Science Education and Technology, 19(6), 553-564. 
Jang, S.-J., \& Chen, K.- C. (2013) Development of an instrument to assess university students’ perceptions of their science instructors' TPACK. Journal of Modern Education Review, 3(10), 771-783.

Jang, S.-J., \& Tsai, M.-F. (2012). Exploring the TPACK of Taiwanese elementary mathematics and science teachers with respect to use of interactive whiteboards. Computers \& Education, 59(2), 327-338.

Jang, S.-J., Tsai, M.-F., \& Chen, H.-Y. (2013). Development of PCK for novice and experienced university physics instructors: A case study. Teaching in Higher Education, 18(1), 27-39.

Jaskyte, K., Taylor, H., \& Smariga, R. (2009). Student and faculty perceptions of innovative teaching. Creativity Research Journal, 21(1), 111-116.

Jimoyiannis, A. (2010). Designing and implementing an integrated technological pedagogical science knowledge framework for science teachers' professional development. Computers \& Education, 55(3), 1259-1269.

Koh, J., Chai, C. S., \& Tay, L. Y. (2014). TPACK-in-action: Unpacking the contextual influences of teachers' construction of technological pedagogical content knowledge (TPACK). Computers \& Education, 78(5), 20-29.

Koh, J., Chai, C. S., \& Tsai, C. C. (2010). Examining the technological pedagogical content knowledge of Singapore preservice teachers with a large-scale survey. Journal of Computer Assisted Learning, 26(6), 563-573.

Koh, J., Chai, C. S., \& Tsai, C.-C. (2013). Examining practicing teachers’ perceptions of technological pedagogical content knowledge (TPACK) pathways: A structural equation modeling approach. Instructional Science, 41(4), 793-809.

Kopcha, T. J. (2010). A systems-based approach to technology integration using mentoring and communities of practice. Educational Technology Research \& Development, 58(2), 175-190.

Lee, M. H., \& Tsai, C. C. (2010). Exploring teachers’ perceived self efficacy and technological pedagogical content knowledge with respect to educational use of the world wide web. Instructional Science, 38(1), 1-21.

Lin, T. C., Tsai, C. C., Chai, C. S., \& Lee, M. H. (2013). Identifying science teachers’ perceptions of technological pedagogical and content knowledge (TPACK). Journal of Science Education and Technology, 22(3), 325-336.

Marshall, D., \& Linder, C. (2005). Students' expectations of teaching in undergraduate physics. International Journal of Science Education, 27(10), 1255-1268.

Mishra, P., \& Koehler, M. J. (2006). Technological pedagogical content knowledge: A framework for teacher knowledge. Teachers College Record, 108(6), 1017-1054.

National Research Council (1996). National science education standards. Washington, DC: National Academy Press.

Niess, M. L. (2005). Preparing teachers to teach science and mathematics with technology: Developing a technology pedagogical content knowledge. Teaching and Teacher Education, 21(5), 509-523.

Nilsson, P. (2008). Teaching for understanding: The complex nature of pedagogical content knowledge in pre-service education. International Journal of Science Education, 30(10), 1281-1299.

Schmidt, D. A., Baran, E., Thompson, A. D., Mishra, P., Koehler, M. J., \& Shin, T. S. (2009). Technological pedagogical content knowledge (TPACK): The development and validation of an assessment instrument for preservice teachers. Journal of Research on Technology in Education, 42(2), 123-149.

Shih, C-L., \& Chuang, H.-H. (2013). The development and validation of an instrument for assessing college students' perceptions of faculty knowledge in technology-supported class environments Computers \& Education, 63(1), 109-118.

Shulman, L. (1986). Those who understand: Knowledge growth in teaching. Educational Researcher, 15(2), 4-14.

Shulman, L. (1987). Knowledge and teaching. Harvard Educational Review, 57(1), 1-22.

Tuan, H., Chang, H., Wang, K., \& Treagust, D. (2000). The development of an instrument for assessing students' perceptions of teachers' knowledge. International Journal of Science Education, 22(4), 385-398.

Van Driel, J., Verloop, N., \& de Vos, W. (1998). Developing science teachers' pedagogical content knowledge. Journal of Research in Science Teaching, 35(6), 673-695.

Voogt, J., Fisser, P., Roblin, N. P., Tondeur, J., \& van Braak, J. (2013). Technological pedagogical content knowledge - a review of the literature. Journal of Computer Assisted Learning, 29, 109-121. 
Corresponding author: Syh-Jong Jang, jang6812@yahoo.com.tw

Australasian Journal of Educational Technology (c) 2016.

Please cite as: Jang, S-J., \& Chang, Y. (2016). Exploring the technological pedagogical and content knowledge (TPACK) of Taiwanese university physics instructors. Australasian Journal of Educational Technology, 32(1), 107-122. 


\section{Appendix A \\ Questionnaire on University Students' Perceptions of Science Instructor's TPACK}

\section{Subject Matter Knowledge (SMK)}

1. I think my teacher knows the content he/she is teaching.

2. I think my teacher explains clearly the content of the subject.

3. I believe my teacher knows how theories or principles of the subject have been developed.

4. I think my teacher selects the appropriate content for students.

5. I believe my teacher knows the answers to questions that we ask about the subject.

6. I think my teacher explains the impact of subject matter on society.

7. I think my teacher knows the whole structure and direction of this subject matter.

8. I think my teacher makes me clearly understand objectives of this course.

9. I believe my teacher pays attention to students' reaction during class and adjusts his/her teaching attitude.

10. I think my teacher's belief or value in teaching is positive.

\section{Instructional Representation \& Strategies (IRS)}

11. I think my teacher uses appropriate examples to explain concepts related to subject matter.

12. I think my teacher uses familiar analogies to explain concepts of subject matter.

13. I believe my teacher's teaching methods keep me interested in this subject.

14. I think my teacher provides opportunities for me to express my views during class.

15. I think my teacher uses demonstrations to help explaining the main concept.

16. I believe my teacher uses a variety of teaching approaches to transform subject matter into comprehensible knowledge.

17. I think my teacher adopts group discussion or cooperative learning.

18. I think my teacher provides an appropriate interaction or good atmosphere.

19. I think my teacher creates a classroom circumstance to promote my interest for learning.

20. I think my teacher prepares some additional teaching materials.

\section{Knowledge of Students' Understanding (KSU)}

21. I believe my teacher realises students' prior knowledge before class.

22. I believe my teacher knows students' learning difficulties of subject before class.

23. I think my teacher's questions evaluate my understanding of a topic.

24. I think my teacher's assessment methods evaluate my understanding of the subject.

25. I think my teacher uses different approaches (questions, discussion, etc.) to find out whether I understand.

26. I believe my teacher's assignments facilitate my understanding of the subject.

\section{Technology Integration \& Application (TIA)}

27. I think my teacher knows how to use multimedia (e.g. PowerPoint and animation, etc.) for teaching. 28. I believe my teacher knows how to use web technologies (e.g. teaching website, Blog, and distance learning) for teaching.

29. I believe my teacher is able to choose multimedia and web technologies which enhance his/her teaching for a specific course unit.

30. I think my teacher is able to use technology to enhance our understanding and learning of lessons.

31. I think my teacher is able to use technology to enrich the teaching content and materials.

32. I think my teacher is able to integrate content, technology, and teaching methods in his/her teaching.

33. I believe my teacher is able to choose diverse technologies and teaching methods for a specific course unit. 


\section{Appendix B}

\section{Questionnaire on University Instructors' self-perceptions of TPACK}

\section{Subject Matter Knowledge (SMK)}

1. I know the content I am teaching.

2. I explain clearly the content of the subject.

3. I know how theories or principles of the subject have been developed.

4. I select the appropriate content for students.

5. I know the whole structure and direction of this subject matter.

6. I make students clearly understand objectives of this course.

7. I know students' learning difficulties of subject before class.

8. My questions can evaluate students' understanding of a topic.

\section{Instructional Representation and Strategies (IRS)}

9. My teaching methods keep students interested in this subject.

10. I use demonstrations to help explaining the main concept.

11. I use a variety of teaching approaches to transform subject matter into comprehensible knowledge.

12. I adopt group discussion or cooperative learning.

13. I provide an appropriate interaction or good atmosphere.

14. I create a classroom circumstance to promote students' interest for learning.

15. I use different approaches (questions, discussion, etc.) to find out whether students understand.

16. My belief or value in teaching is active and aggressive.

\section{Technology Integration \& Application (TIA)}

17. I know how to use multimedia (e.g. PowerPoint and animation, etc.) for teaching.

18. I know how to use web technologies (e.g. teaching website, Blog, and distance learning) for teaching.

19. I am able to choose multimedia and web technologies which enhance my teaching for a specific course unit.

20. I am able to use technology to enhance students' understanding and learning of lessons.

21. I am able to use technology to enrich the teaching content and materials.

22. I am able to integrate content, technology, and teaching methods in my teaching.

23. I am able to choose diverse technologies and teaching methods for a specific course unit. 